\title{
Early Initiation of Breastfeeding Among Postpartum Mothers at Two Rwandan Hospitals
}

Joella Mukashyaka1*, Rose Mukarubayiza ${ }^{1}$, Emmanuel Habumugisha ${ }^{2}$, Francois-Xavier Sunday ${ }^{1}$, Kellen Muganwa ${ }^{1}$, Valens Mbarushimana ${ }^{1}$, Pamela Meharry 1,3

${ }^{1}$ School of Nursing and Midwifery, College of Medicine and Health Sciences, University of Rwanda, Kigali, Rwanda

${ }^{2}$ Department of General Nursing, University of Gitwe, Rwanda

${ }^{3}$ Department of Women's, Children's and Family Health Services, University of Mlinois, Chicago, USA

*Corresponding author: Joella Mukashyaka. School of Nursing and Midwifery, College of Medicine and Health Sciences, University of Rwanda, Remera Campus, 11KG47, Kigali, Rwanda. Email: joellashyaka@gmail.com.

\begin{abstract}
Background

Breastfeeding in the first hour post birth can decrease neonatal morbidity and mortality. Disease prevention and health outcomes differ immensely between newborns who receive human milk and those who do not. Rwanda has high breastfeeding rates, though factors associated with early initiation of breastfeeding (EIBF) are unknown.
\end{abstract}

\section{Objective}

To assess factors associated with EIBF among mothers in immediate postpartum units at two hospitals.

\section{Methods}

A cross-sectional study design and a convenience sample of 187 mothers were used. An intervieweradministered questionnaire was used for data collection. A Chi-square test showed the relationship between EIBF and sociodemographic factors.

\section{Results}

The findings showed less than one quarter $(20.5 \%)$ breastfed within the first hour after birth. The majority was $<25$ years $(52.4 \%)$, had some primary education $(27.7 \%)$ employed $(66.7 \%)$, urban dweller $(58.1 \%)$, attendance of one ANC visit or more (81.3\%), vaginal birth (58.8\%), and did not receive EIBF health education $(92.0 \%)$. The majority $(78.5 \%)$ was too tired to initiate breastfeeding, and many supplemented $(41.9 \%)$ due to perceived insufficient breastmilk.

\section{Conclusion}

Most mothers did not initiate breastfeeding within the first hour after birth. Sociodemographic factors were associated with EIBF. A program to promote, protect, and support EIBF is urgently needed the community.

Rwanda J Med Health Sci 2020;3(2):181-192

Keywords: Breastfeeding, early initiation, neonates, morbidity, mortality, sub-Saharan Africa

\section{BACKGROUND}

Early initiation of breastfeeding (EIBF) within one hour of birth begins a strong defense against neonatal morbidity and mortality.[1] In 2017, 2.5 million neonates died during the first month after birth. However, EIBF is the single most effective lowcost intervention and best practice to reduce neonatal morbidity and mortality, especially in developing countries.[2] Breastfeeding (BF) within the first hour after birth is critical for newborn survival and BF's establishment over the long term.[1] However, the prevalence of EIBF is only about $50 \%$ at the global level, and many mothers face considerable challenges.[3]

Globally, the survival rate of children under-five has improved significantly over the past two decades, except for neonates, from birth to 28 days.[2] The neonatal period is the riskiest time of a child's life, 
so getting an early start on exclusive BF (by not using supplements, even water, for six months), helps buffer the infants' vulnerability while their immune system is maturing to fight disease.[1-3] New parents, relatives, and healthcare providers (HCPs) need to know about the risks of not BF, particularly in developing countries, as disease prevention and health outcomes differ immensely between newborns who receive natural human milk and those who do not.[3] A recent meta-analysis by Khan et al. [4] demonstrated that initiating BF after the first hour, instead of within the first hour, doubles neonatal mortality risk. Furthermore, neonates who are only partially breastfed in the first month are at higher risk of infection-related mortality (sepsis, acute respiratory and gastrointestinal infections), and all-cause mortality than neonates exclusively breastfed.[4]

"This inequality persists until later in life", states Victora et al.[3] from a meta-analysis published in the Lancet. There are substantial benefits to BF, especially immunological and nutritional benefits for both the mother and offspring. The World Health Organization (WHO) recommendation is, to begin with, EIBF, continue BF exclusively for six months, and then add complementary foods to BF until the child is two years of age or older.[2] Children whom $\mathrm{BF}$ for a year have higher intelligence, and reap other potential benefits later in life, compared to $\mathrm{BF}$ less than a year.[3] A prospective, birth cohort study in Brazil followed a large population $(n=3493)$ to age 30 years and found that children who breastfed for 12 months or more had higher intelligence quotient (IQ) scores, increased years of education, and higher monthly incomes than those breastfed for less than a month.[5]

A meta-analysis of 29 sub-Saharan African countries by Issaka et al.[6] found that the prevalence of EIBF using Demographic and Health Surveys (2010-2015) ranged from a low $37.84 \%$ in Central Africa to a high $69.31 \%$ in Southern Africa. Rwanda had a prevalence of $81.51 \%$, second only to Malawi at 95.64\%. [6] And had an exclusive BF rate of $87.3 \%$ in $2015 .[7]$

Early initiation of breastfeeding is associated with newborn survival.[1-4] Considering Rwanda's effort to improve $\mathrm{BF}$ rates and duration, research needs to be translated into evidence-based practice (EBP) to help meet the Sustainable Development Goal (SDG3) on Neonatal Mortality,[8] and Rwanda's goal of becoming a middle-income country by 2035.[9] The study aimed to assess factors associated with EIBF among mothers in immediate postpartum units at two district hospitals in Rwanda.

\section{METHODS}

\section{Design}

A descriptive cross-sectional design was used to assess BF initiation among mothers in the immediate postpartum ward. The study was conducted at Kabgayi District Hospital with rural and urban populations in Muhanga District, and Kacyiru District Hospital located in Gasabo District, Kigali City, in an urban area. Data collection was conducted from March to May 2019.

\section{Participants' recruitment}

Eligible participants included mothers on the immediate postpartum units at two selected hospitals. A simple random purposive sampling technique was used to recruit mothers. The HIV positive mothers were excluded if they chose not to breastfeed, had premature neonates hospitalized in the NICU, or unwilling to disclose their information.

The sample size was based on the population size for one month at each hospital and Taro Yamane's formula for seven weeks of data collection; the result was 350 mothers at the two hospitals. $\mathrm{N}=$ the population size, $\mathrm{n}=$ the sample size, $\mathrm{e}=$ sampling error, 95\% confidence level and significance level of $\mathrm{p}=0.5$.

$$
\begin{gathered}
\mathrm{P}=5 \%, \mathrm{e}=0.05, \mathrm{~N}=350 \\
\mathrm{n}=350 /\left[1+350 *(0.05)^{2}\right]=186.66667 \approx 187
\end{gathered}
$$

All 187 mothers were in the immediate postpartum service, with 100 at Kabgayi District Hospital and 87 at Kacyiru District Hospital. The mothers were recruited into the study every three days during the seven weeks of data collection.[10]

\section{Measures}

The questionnaire was adapted from published literature on the topic, including a study conducted in Kenya by Mututho et al.[10] The validated questionnaire used closed-ended questions and was composed of four sections, including demographic characteristics and the participant's perception of early initiation of breastfeeding.

Section 1: The sociodemographic characteristics included age, level of education, residence, religion, employment, gravidity, mode of delivery, and location of ANC visit (8 items). The person who fed the neonate a supplement in the first hour, and reasons for the initial delay in neonate $\mathrm{BF}$ ( 3 items). All items were measured in frequencies.

Section 2: The association between EIBF and social demographic characteristics included the importance of early $\mathrm{BF}$ health education during ANC, the risks of giving water, formula, or other 
supplements to the neonate in the first hour after birth, not BF ( 3 items). The variables were measured using regression analysis with a p-value: Chisquare test.

Section 3: The variable neonatal feedings included five items; $\mathrm{BF}, \mathrm{BF}$ and formula, formula only, other fluids, and did not know. Another variable, the reason for a supplement, if any, also had five items; Limited understanding of breast function, Limited breastmilk (colostrum), neonate's strong suck or latching reflex, availability of other fluid, and neonate's feeding difficulty (nipple status). Data were measured in frequencies.

Section 4: The person who fed the neonate (1 item), and reasons for the initial delay in neonate BF (1 item). Both variables were presented in frequencies.

\section{Pilot test}

A pilot test was conducted on 10 mothers to test for the feasibility of the study at Kacyiru and Kabgayi District Hospitals. These mothers were not included in the main study, though based on their comments and observations, adjustments were made to the questionnaire.

\section{Data collection}

After obtaining permission to conduct the study from the university and the two hospitals, the investigator approached the maternity wards' unit managers to discuss the best way and time to access postpartum mothers. Mothers were approached in their rooms and invited to participate in the study. The purpose of the study, confidentiality, and reassurance they could withdraw at any time was explained. Mothers willing to participate then voluntarily signed the consent form. The investigator used the interviewer-administered questionnaire to collect data, which took about 7-12 minutes for each participant, depending on the individual. All data collection was conducted during regular working hours by the investigator, and questionnaires were checked for completeness.

\section{Data analysis}

Data were checked, coded, and entered into the Statistical Package for Social Sciences (SPSS), Version 23, for analysis. Descriptive statistics such as frequencies and percentages were used to describe sociodemographic, sources of $\mathrm{BF}$ information, maternal knowledge, and feeding practices. A Chi-square $\left(\mathrm{X}^{2}\right)$ was used to test the association between sociodemographic factors and knowledge of EIBF and ANC health education. A binary regression analysis was used to ascertain associations with EIBF. A p-value of $\leq 0.05$ was considered statistically significant.

\section{Ethical considerations}

Ethical clearance was obtained from the University of Rwanda College of Medicine and Health Sciences, Institutional Review Board, and the two hospitals used as study sites. Informed written or thumbprint consent was obtained before data collection and prearranged to the mothers willing to participate.

\section{RESULTS}

Data were collected from 187 mothers in the immediate postpartum units of two hospitals in Rwanda to assess the different factors that affect BF initiation. The sociodemographic characteristics are presented in Table 1. 
Table 1. Sociodemographic characteristics of participants $(n=187)$

\begin{tabular}{|c|c|}
\hline Variables & n (\%) \\
\hline \multicolumn{2}{|l|}{ Age (years) } \\
\hline $18-24$ & 77 (41.2) \\
\hline $25-34$ & 69 (36.9) \\
\hline $35-44$ & $18(9.6)$ \\
\hline$\geq 45$ & $23(12.3)$ \\
\hline \multicolumn{2}{|l|}{ Education level } \\
\hline No formal education & $38(20.3)$ \\
\hline Some primary & $53(28.4)$ \\
\hline Completed primary & $28(15.0)$ \\
\hline Some secondary & $24(12.8)$ \\
\hline Completed secondary & $10(5.3)$ \\
\hline$>$ Secondary & $34(18.2)$ \\
\hline \multicolumn{2}{|l|}{ Employment } \\
\hline Employed & $127(67.9)$ \\
\hline Not employed & $60(32.1)$ \\
\hline \multicolumn{2}{|l|}{ Religion } \\
\hline Christian & $146(78.1)$ \\
\hline Muslim & $41(21.9)$ \\
\hline \multicolumn{2}{|l|}{$\begin{array}{l}\text { Musilm } \\
\text { Residence }\end{array}$} \\
\hline Urban & $111(59.4)$ \\
\hline Rural & $76(40.6)$ \\
\hline \multicolumn{2}{|l|}{ Gravidity } \\
\hline Primigravida & $38(20.3)$ \\
\hline Multigravida & $149(79.7)$ \\
\hline \multicolumn{2}{|l|}{ ANC visits } \\
\hline 0 & $17(9.1)$ \\
\hline 1 & $35(18.7)$ \\
\hline 2 & $89(47.6)$ \\
\hline 3 & $28(15.0)$ \\
\hline$\geq 4$ & $18(9.6)$ \\
\hline \multicolumn{2}{|l|}{ Mode of delivery } \\
\hline SVD & $110(58.8)$ \\
\hline $\mathrm{CS}$ & $77(41.2)$ \\
\hline \multicolumn{2}{|l|}{ ANC health education } \\
\hline Yes & $15(8.0)$ \\
\hline No & $172(92.0)$ \\
\hline
\end{tabular}

ANC: Antenatal Care SVD: Spontaneous Vaginal Delivery CS: Caesarean

The above table shows the sociodemographic characteristics of the participants. The majority $(41.2 \%)$ was aged $18-24$ years, had some primary school education $(28.4 \%)$, was employed $(67.9 \%)$, Christian $(78.1 \%)$, and lived in an urban area (59.4\%). The majority (47.6\%) had two ANC visits, was multigravida (79.7\%), delivered by SVD (60.4\%), and did not receive EIBF health education $(92.0 \%)$. 


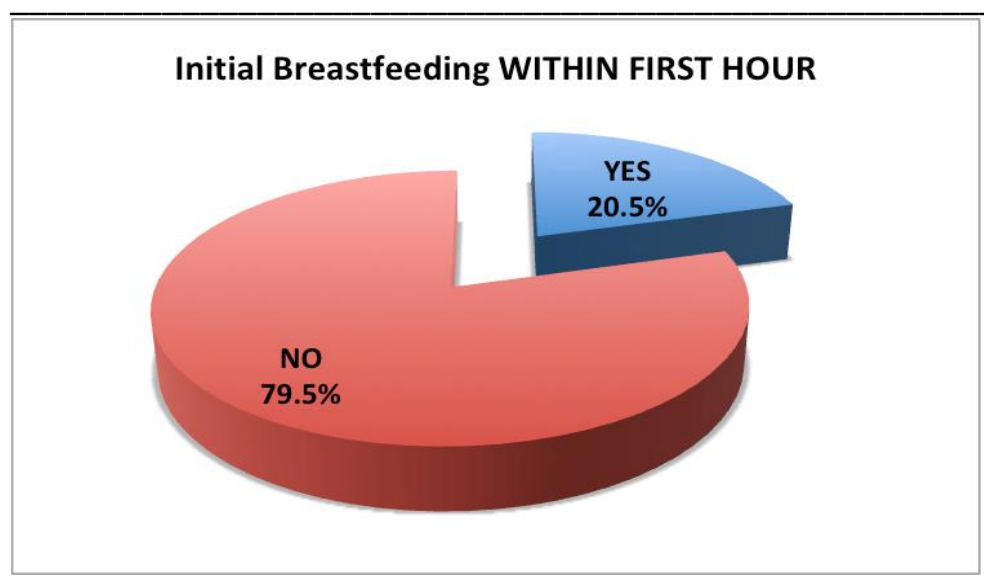

Figure 1. Initial breastfeeding in first hour of birth

Figure 1. Less than a quarter (20.5\%) of neonates received early initiation of breastfeeding.

Table 2. Neonatal feeding and reason for supplement $(\mathbf{n}=187)$

\begin{tabular}{ll}
\hline Variables & $\mathbf{n}(\%)$ \\
\hline Neonate's Feeding provided & \\
Breastfeeding only & $120(64.2)$ \\
Breastfeeding and formula & $29(15.5)$ \\
Formula only & $21(11.2)$ \\
Other fluid (glucose) & $10(5.3)$ \\
Do not know & $7(3.8)$ \\
Reasons for supplements & \\
Limited understanding of breast function & $35(18.3)$ \\
Limited breastmilk - colostrum & $80(41.9)$ \\
Neonate's strong suck or latching reflex & $30(15.7)$ \\
Availability of other fluid & $20(10.5)$ \\
Neonate's feeding difficulty - nipple status & $22(12.5)$ \\
\hline
\end{tabular}

Table 2 shows the majority of participants used only breastfeeding (64.2\%). Others used a combination of breastfeeding and a supplement $(20.8 \%)$, or formula $(11.2 \%)$, and others did not know what had been given $(3.8 \%)$. The main reasons for giving supplements were due to perceived limited breastmilk (41.9\%), limited understanding of breast function (18.3\%), or neonate's vigorous suckling or latching reflex $(15.7 \%)$. 


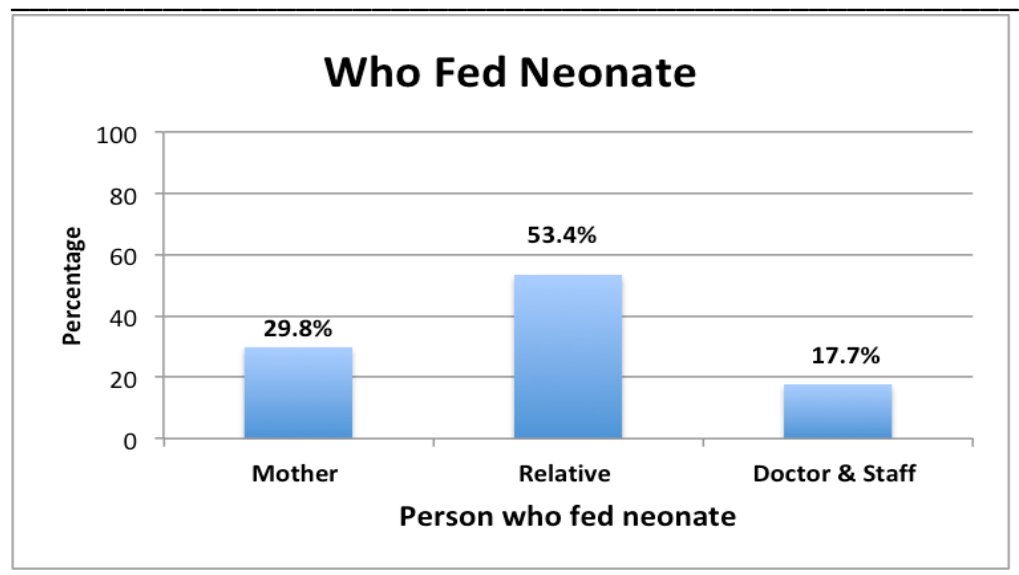

Figure 2. Person who fed neonate supplement in first hour

Figure 2 shows who fed a supplement to the neonate. Over a quarter $(29.8 \%)$ of mothers who fed the supplement, over half (53.4\%) of relatives assisted supplement giving, and a limited proportion $(17.7 \%)$ of doctors or other staff intervened for feeding the neonate.

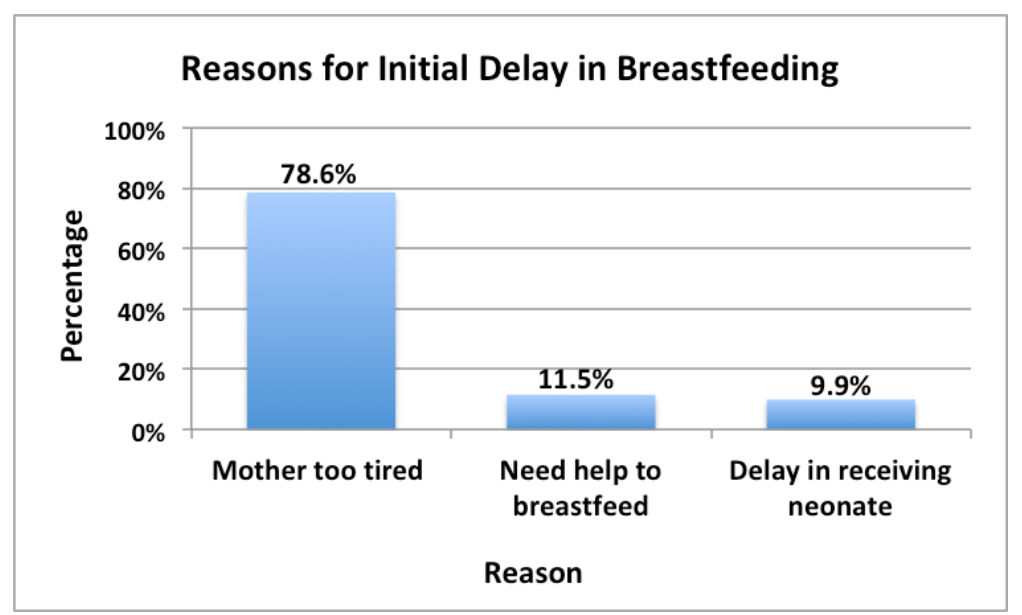

Figure 3. Reasons for initial delay in neonate breastfeeding

Figure 3 shows the reasons why the neonate did breastfeed. Of the neonates that received supplements, the majority $(78.6 \%)$ of mothers were too tired to breastfeed. Other reasons for supplemental feedings included, neonate needed help to breastfeed $(11.5 \%)$ and not given neonate soon enough $(9.9 \%)$, the reason influencing the not receiving breastmilk. 
Table 3. Association between EIBF and sociodemographic characteristics (n=187)

\begin{tabular}{|c|c|c|c|c|c|}
\hline Variables & Yes n (\%) & No $n(\%)$ & Total & $x^{2}$ & $\mathbf{p}$ \\
\hline Age (years) & & & & 18.737 & 0.002 \\
\hline $18-24$ & $20(44.4)$ & $57(40.1)$ & 77 (41.2) & & \\
\hline $25-34$ & $25(55.6)$ & $44(31.0)$ & $69(36.9)$ & & \\
\hline $35-44$ & $0(0)$ & $18(12.7)$ & $18(9.6)$ & & \\
\hline$\geq 45$ & $0(0)$ & $23(16.2)$ & $23(12.3)$ & & \\
\hline Education & & & & 15.916 & 0.005 \\
\hline No formal & $14(31.1)$ & $24(16.9)$ & $38(20.3)$ & & \\
\hline Some primary & 15 (33.3) & $38(26.8)$ & $53(28.3)$ & & \\
\hline Completed primary & $9(20.0)$ & 19 (13.4) & $28(15.0)$ & & \\
\hline Some secondary & $0(0)$ & 24 (16.9) & $24(12.8)$ & & \\
\hline Completed secondary & $0(0)$ & $10(7.0)$ & $10(5.3)$ & & \\
\hline > Secondary & 7 (15.6) & $27(19.0)$ & $34(18.2)$ & & \\
\hline Employment & & & & 0.327 & 0.345 \\
\hline Yes & $29(64.4)$ & $98(69.0)$ & 127 (67.9) & & \\
\hline No & $16(35.6)$ & $44(31.0)$ & $60(32.1)$ & & \\
\hline Religion & & & & 0.595 & 0.291 \\
\hline Christian & 37 (82.2) & $109(76.8)$ & $146(78.1)$ & & \\
\hline Muslin & $8(17.8)$ & $33(23.3)$ & 41 (21.9) & & \\
\hline Residence & & & & 12.841 & 0.001 \\
\hline Urban & $37(82.0)$ & $74(52.1)$ & $111(59.4)$ & & \\
\hline Rural & $8(17.8)$ & 68 (47.9) & $76(40.6)$ & & \\
\hline ANC visits & & & & 1.241 & 0.538 \\
\hline 0 & $3(6.67)$ & $14(9.9)$ & $17(9.1)$ & & \\
\hline $1-3$ & $36(80.00)$ & $116(81.7)$ & $152(81.3)$ & & \\
\hline $4+$ & $6(13.33)$ & $12(8.5)$ & $18(9.6)$ & & \\
\hline ANC Health Education & & & & 5.168 & 0.023 \\
\hline Yes & $0(0.0)$ & $15(10.6)$ & $15(8.0)$ & & \\
\hline No & $45(100)$ & $127(89.4)$ & $172(91.9)$ & & \\
\hline Gravidity & & & & 15.113 & 0.001 \\
\hline Primigravida & $0(0)$ & $38(26.8)$ & $38(20.3)$ & & \\
\hline Multigravida & $45(100)$ & $104(73.2)$ & $149(79.7)$ & & \\
\hline Mode of delivery & & & & 0.540 & 0.043 \\
\hline SVD & $26(57.8)$ & 87 (61.3) & $113(60.4)$ & & \\
\hline $\mathrm{CS}$ & 19 (42.2) & $54(38.0)$ & $73(39.0)$ & & \\
\hline
\end{tabular}

ANC: Antenatal Care; SVD: Spontaneous Vaginal Delivery; CS: Caesarean

Table 3 shows the association between EIBF and sociodemographic characteristics. There was a statistical significance between EIBF and age $\left(\mathrm{X}^{2}=18.737 ; \mathrm{p}=0.002\right)$, education level $\left(\mathrm{X}^{2}=\right.$ $15.916, \mathrm{p}=0.005)$, residence $\left(\mathrm{X}^{2}=12.841, \mathrm{p}=0.001\right)$ gravidity $\left(\mathrm{X}^{2}=15.113, \mathrm{p}=0.001\right)$, the mode of delivery $\left(X^{2}=0.54, p=0.043\right)$ and ANC health education $(X 2=5.168, p=0.023)$. 


\section{DISCUSSION}

The cross-sectional study results revealed that only a fifth of the 187 mothers' breastfed their newborns within the first hour. The sociodemographic characteristics that indicated statistical significance of decreased EIBF included younger than 25 years $(\mathrm{X} 2=18.737, \mathrm{p}=0.002)$, no formal education or did not complete primary school $(\mathrm{X} 2=15.916, \mathrm{p}=$ $0.005)$, lived in an urban area $(\mathrm{X} 2=12.841, \mathrm{p}=$ $0.001)$, primigravida $(\mathrm{X} 2=15.113, \mathrm{p}=0.001)$ and ANC health education (X2 $=5.168, \quad \mathrm{p}=0.023)$. Similarly, a study in Lira District, Northern Uganda, with mother-child pairs ( $\mathrm{n}=930$ ), mothers who had completed secondary education had lower rates of delayed initiation of $\mathrm{BF}$ when compared to those with no education (AOR 0.54, 95\% CI 0.30-0.96). [11] In contrast, in India, mothers with more education were at increased risk of cessation of exclusive $\mathrm{BF}$ than mothers with no formal education (OR 1.18, 95\% CI 1.03-1.35).[12]

Maternal complications were the leading cause of $\mathrm{CS}\left(\mathrm{X}^{2}=0.54, \mathrm{p}=0.043\right)$, and a major reason for delayed breastfeeding. The practice of EIBF postsurgery is rarely practiced in Rwanda. Similarly, in Northern Uganda, a study showed that $48.2 \%$ of newborns had their initial BF delayed due to CS, and this delay was 11 times more likely than mothers with an SVD (AOR 11.10, 95\% CI 3.7333.04, $\mathrm{p}<0.001) \cdot[11]$

The risk of delayed BF may be decreased with ANC attendance $\left(\mathrm{X}^{2}=7.64, \mathrm{p}=0.006\right)$, and increased frequency of ANC visits $\left(X^{2}=3.48, p=0.007\right)$. This finding suggests that attending two ANC visits $(47.6 \%)$ is not adequate to cover the full package of ANC care and hence reinforces the need to continue encouraging completion of four ANC visits or more. $[13,14]$ The WHO recommendation for pregnant women is now eight contacts with healthcare personnel during pregnancy.[2] Counseling is helpful during ANC as most mothers make decisions about infant feeding early in pregnancy. Therefore, HCPs should educate mothers about the substantial health benefits and impact of infant feeding and address potential obstacles to BF at the first ANC visit.[15] Counseling during ANC visits allows HCPs to empower mothers and their families to initiate BF in a timely fashion after birth,[16] and counseling postpartum also increases time BF.[17]

\section{First breastfeeding of neonate after birth}

The findings showed that nearly a quarter $(20.5 \%)$ of neonates were able to breastfeed within the first hour after birth; therefore, the majority $(79.5 \%)$ breastfed after one hour (Figure 1). Similarly, a study in Western Nepal using the Demographic and Health Survey with mother-in-pairs $(n=735)$, reported $42.2 \%$ had EIBF. In contrast, a study in Kasarani, Kenya [10] showed that $64.3 \%$ of mothers $(n=220)$ were able to do EIBF after birth. Reasons for delayed BF in Nepal included low-birth weight (LBW) infants, CS deliveries, births attended by traditional birth attendants, and ethnically disadvantaged families. [18] Whereas in Northern Uganda, discarding initial breast milk was significantly associated with delayed BF initiation (AOR 2.02 95\% CI 1.41-2.88).[11]

The initiation of BF within the first hour ensures the newborn begins feeding with the mother's natural colostrum, which provides essential nutritional and immunologic benefits to newborns at a very vulnerable period.[19] Colostrum is particularly high in immunoglobulin that protect the newborn transitioning from the safety of their mother to the external environment and exposure to pathogens and potential disease.[19] Furthermore, delays in $\mathrm{BF}$ initiation interfere with the flow of mature breastmilk, putting the neonate at risk for dehydration or excessive weight loss after birth.[13]

Usually, mothers who give birth via SVD have their newborns placed in skin-to-skin contact (SSC) in the prone position for at least an hour, and this allows newborns to find the breast and begin suckling. [16] In our study, $110(60.4 \%)$ mothers had an SVD, yet less than a quarter $(20.5 \%)$ reported BF in the first hour. The rates of EIBF are higher among mothers who give birth in a health facility than outof-hospital births. $[1,2,4]$ In Uganda, EIBF was delayed if the mother was solely responsible for initiating $\mathrm{BF}$ herself (AOR 1.73 95\% CI [1.332.26]).[11] First-time mothers should be assisted in recognizing when their newborns are ready to breastfeed, and HCPs should be able to help when needed.[10,15] A concerted effort is needed to reeducate midwives, nurses, and doctors working with new mothers about the dangers of delaying breastfeeding.

\section{Neonatal feeding}

While the majority (64.2\%) of participants breastfed and did not give a supplement, nearly a third $(32.0 \%)$ did give the newborn formula or glucose water (Table 2). A limited proportion (10.5\%) used a supplement just because it was available. However, the main reason for using a supplement $(41.9 \%)$ was because the mother thought there was a limited amount of colostrum present in her breasts. 
Giving a supplement - whether it is a formula or other fluid - has no anti-infective properties and is therefore deficient in protecting the newborn from disease. Furthermore, it can be harmful if the supplement is not suitable for human infants, such as unmodified milk from cows, goats, and sheep. [20] Moreover, a supplement or reconstituted milk powder with contaminated water may cause significant health problems for the newborn, including life-threatening neonatal sepsis.[20-22]

\section{Reasons for neonate not receiving breastmilk}

The majority $(78.6 \%)$ reported that the delay in EIBF was due to fatigue (Figure 3). Other participants said that their neonate was not given to them quickly enough after the birth; the neonate fell asleep, or needed special care. A qualitative study in India discovered that the barriers to $\mathrm{BF}$ included the lack of knowledge on BF benefits, lack of proper technique, breast abnormalities (inverted nipples), neonatal or maternal complications, and cultural practices.[23] The cultural practices that created barriers in India included giving pre-lacteal supplements, gender discrimination, and a busy workload for HCPs as more women are now delivering in hospitals.[23]

Our findings showed no association between EIBF and ANC because of the small sample size, in contrast to a study in Ethiopia, which showed an association between EIBF and ANC. [29] The EIBF and ANC with health education on the importance of early BF were significant $\left(X^{2}=5.1681, p=0.023\right)$ and ANC education on the risks of giving any fluid other than breastmilk in the first six months $\left(\mathrm{X}^{2}=\right.$ $0.03, p=0.004)$. This finding indicates a need for more $\mathrm{BF}$ education and promotion in the communities. One significant step would be to integrate the Baby-Friendly Hospital Initiative (BFHI) into our hospitals.[24] The BFHI program was developed by UNICEF and WHO in 1991 to promote $\mathrm{BF}$ as it is the best food source for newborns. There are 10 specific steps to becoming a Baby-Friendly facility, beginning with Step 1 and the need for a policy that supports BF.[24] Step 2 is a critical management mandate requiring all $\mathrm{HCPs}$ and staff working in maternity to have "sufficient knowledge, competence, and skills to support breastfeeding". Step 3 is a clinical practice mandate that HCPs and staff discuss the "importance and management of breastfeeding with pregnant women and their families".[24]

Over three quarters $(78.6 \%)$ of the mothers in our study indicated they were tired after the birth. In a Baby-Friendly Hospital, tired new mothers are encouraged (and assisted) to turn on their side (left or right side), which allows the mother and newborn to breastfeed in the side-lying position. The newborn would be positioned facing the mother on the bed, to $\mathrm{BF}$ on the mother's lower breast. A towel or blanket is placed behind the newborn for safety purposes and a pillow or blanket behind the mother's back for support. At the next BF in 2-3 hours, the mother would be encouraged (assisted if a CS) to turn to the other side, and the newborn would be assisted to BF from the lower breast.

The use of assessment tools, such as the BF selfappraisal tool (e.g., LATCH, IBFAT), is beneficial in evaluating new mothers' BF techniques. These tools should be used regularly to evaluate and monitor if the hospitals are keeping up to the required standards.[25] For any training carried out, there should be a regular follow-up as recommended by the WHO.[1,14]

Our findings suggest that it is vital to raise awareness of the importance of EIBF to the Rwandan community, especially to pregnant women and their relatives. There is a need to increase all strategies such as involvement of health policymakers in EIFB, improving hospital practices, ANC visits, and community health education using mass media or mother support groups, and BabyFriendly Hospital Initiative (BFHI) that emphasize the importance of $\mathrm{BF}$ and early initiation, as well as promoting exclusive breastfeeding. To better promote EIBF, we should provide individual support to mothers with complications, CS deliveries, and all BF mothers who have an SVD and stable newborn post-birth.

Nearly all mothers in this study appeared to require HCP assistance in some form. Assistance was needed with more accurate $\mathrm{BF}$ information and timely help with positioning so mothers could rest while $\mathrm{BF}$, help with positioning the newborn and correcting the latch to prevent nipple soreness, and expressing colostrum to show the mother that she had adequate breastmilk for her newborn.

Infants of all sizes and gestation should be given human-milk as it provides the best nutrients and hormones, and boosts the immune system and gut microbiome.[20] Preterm infants may need the breastmilk to be fortified to increase the energy, minerals, and protein content until the infant is over two kilograms or fully breastfed.[20] Mothers with infants in the Neonatal Intensive Care Unit (NICU) are encouraged to breastfeed or give breast milk, as it decreases the time to establish full enteral feedings, decreases late-onset sepsis, and the incidence of necrotizing enterocolitis (NEC), and enhances bonding between mother and infant.[20] 
If these recommendations were to be implemented, mothers who initiate BF within one hour would significantly increase, and the use of supplements would decrease.[26] Importantly, our findings further demonstrate that although guidelines are an essential starting point for improving care, training HCPs on any set of guidelines may raise their knowledge, though not markedly improve practice. $[11,27]$

Bridging this gap between knowledge and practice is more about 'organizing processes of care' within health facilities to optimize adherence to set evidence-based guidelines and ensure consistency in care delivery.[5,28] Some of the promising concepts to address these issues have been the deliberate application of improvement principles in healthcare settings. It is therefore paramount that beyond training on new guidelines, concerted efforts are made to enable healthcare managers, frontline HCPs, and "BF champions" to build effective care delivery systems that improve quality of care to mothers and newborns.

\section{Limitations}

The study was conducted at two hospitals, and therefore the results cannot be generalized to other parts of Rwanda. A generalization of the findings was also limited due to the small sample size. Although we conducted a pilot to test the feasibility of the study, some mothers might not have understood the questionnaire well. There might have been recall bias from some mothers.

\section{Future research}

Other studies may include more hospitals and a larger sample size, or an interventional study with pre-test and post-test to assess knowledge gained with HCPs and pregnant women. One study [4] identified an important gap in the research and recommended a randomized control trial to assess the timing of $\mathrm{BF}$ initiation and exclusive $\mathrm{BF}$ during the neonatal period. Since this practice is already evidenced-based, the research could be ethically achieved through the significant promotion of $\mathrm{BF}$ in the intervention group and usual care in the control group.

\section{CONCLUSION}

The majority of mothers did not initiate $\mathrm{BF}$ in the first hour after birth. Special attention needs to be focused on mothers who deliver via cesarean, so neonates born via surgical intervention do not miss out on the benefits of early breastfeeding. A program aiming to promote, protect, and support EIBF is urgently needed. ANC visits sensitization is the single best low-cost, effective intervention for promoting and ensuring the EIBF to Rwandan neonates.

\section{Authors' contributions}

JM contributed to the original study, data collection, analysis, and manuscript. PM and RM supervised the research; $\mathrm{HE}$ helped in data collection; VM worked on statistical part and KM, SFX, VM and PM revised the manuscript. All seven authors read the final manuscript.

\section{Conflict of interest}

The authors declare they have no potential or actual conflict of interest.

\section{Acknowledgements}

We acknowledge all participants that made this study successful. Also, a special thank you to the Training, Support, and Access Model for Maternal, Newborn, and Child Health (TSAM-MNCH) Project for their support with this research and manuscript, much thanks to Miss Gasengayire Alphonsine for statistical support.

This article is published open access under the Creative Commons Attribution-NonCommercial NoDerivatives (CC BYNCND4.0). People can copy and redistribute the article only for noncommercial purposes and as long as they give appropriate credit to the authors. They cannot distribute any modified material obtained by remixing, transforming or building upon this article. See https://creativecommons.org/licenses/by-ncnd/4.0/ 


\section{REFERENCES}

1. United Nations Children's Fund and World Health Organisation. Capture the Moment Early initiation of breastfeeding: The best start for every newborn. New York: UNICEF; 2018. ISBN: 978-92-806-4976-5. Available from https://www.unicef.org/publications/files / UNICEF_WHO_Capture_the_moment_EIBF_ 2018.pdf

2. WHO. Guideline: Protecting, promoting and supporting breastfeeding in facilities providing maternity and newborn services [Internet]. 2017. p1-136. Available from: https://apps.who.int/iris/bitstream/handl e/10665/259386/9789241550086eng.pdf?sequence $=1$

3. Victora CG, Bahl B, Barros AJD, França GVA, Horton S, Krasevec J. The Lancet Breastfeeding Series Group. Breastfeeding in the 21st century: epidemiology, mechanisms, and lifelong effect. Lancet. 2016; 387(10017):475-90. DOI: 10.1016/S0140-6736(15)01024-7.

4. Khan J, Vesel L, Bahl R, Martines JC. Timing of breastfeeding initiation and exclusivity of breastfeeding during the first month of life: effects on neonatal mortality and morbidity-A Systematic Review and Metaanalysis. Matern Child Health J. 2015; 19(3):468-79. DOI: $10.1007 / \mathrm{s} 10995-014-$ 1526-8.

5. Santos IS, Barros FC, Horta BL, Menezes AMB, Bassani D, Tovo-Rodrigues L, et al. Breastfeeding exclusivity and duration: trends and inequalities in four populationbased birth cohorts in Pelotas, Brazil, 19822015, International Journal of Epidemiology, 2019; 48(Supp 1):i72i79. DOI:10.1093/ije/dyy159.

6. Issaka AI, Agho KE, Renzaho AM. Prevalence of key breastfeeding indicators in 29 subSaharan African countries: a meta-analysis of demographic and health surveys (20102015). BMJ Open. 2017; 7(10):e014145. DOI: $10.1136 /$ bmjopen

7. Scaling Up Nutrition (SUN). Breastfeeding. Rwanda. ScalingUpNutrition.org. Information from: https://scalingupnutrition.org/news/world -breastfeeding-week-2018/
8. Sustainable Development Goal (SDG3). Ensure healthy lives and promote well-being for all at all ages. Available from: https://sustainabledevelopment.un.org/sd g3

9. World Bank. The World Bank in Rwanda. Economic Overview. 2020. Available from: https://www.worldbank.org/en/country/r wanda/overview

10. Mututho LN, Kiboi WK, Mucheru PK. Factors associated with exclusive breastfeeding in Kenya: a systematic review. International Journal of Community Medicine and Public Health. 2017; 4(12):4358-4362. DOI: $10.18203 / 2394-6040$

11. Mukunya D, Tumwine JK, Nankabirwa V, Ndeezi G, Odongo I, Tumuhamye J, et al. Factors associated with delayed initiation of breastfeeding: a survey in Northern Uganda. Glob Health Action. 2017; 10(1):1410975. DOI: $10.1080 / 16549716$

12. Velusamy V, Premkumar PS, Kang G. Exclusive breastfeeding practices among mothers in urban slum settlements: Pooled analysis from three prospective birth cohort studies in South India. Int Breastfeed J. 2017 ; 12:35. DOI: 10.1186/s13006-0170127-8.

13. Mukarubayiza MR, Gowan M. Educational intervention to increase parental care of preterm neonates at district hospital in Kigali. Rwanda J of Med Health Sci, 2019; 2(2):105-11. DOI:10.4314/rjmhs.v2i2.5

14. Takahashi K, Ganchimeg T, Ota E, Vogel JP. Prevalence of early initiation of breastfeeding and determinants of delayed initiation of breastfeeding: secondary analysis of the WHO Global Survey. Nat Publ Gr [Internet]. $2017 \quad ; \quad$ February):1-10. DOI: $10.1038 /$ srep44868

15. Hassan AA, Taha Z, Ahmed MAA et al. Assessment of initiation of breastfeeding practice in Kassala, Eastern Sudan: a community-based study. Int Breastfeed J. 2018; 13(34). DOI: 10.1186/s13006-0180177-6.

16. World Health Organization. Guideline: Counselling of women to improve breastfeeding practices. Geneva: WHO; 2018. Licence: CC BY-NC-SA 3.0 IGO. Information

from: 
https://apps.who.int/iris/bitstream/handl e/10665/280133/9789241550468-eng.pdf

17. Alebel A, Dejenu G, Mullu G, Abebe N, Gualu $\mathrm{T}$, Eshetie S. Timely initiation of breastfeeding and its association with birthplace in Ethiopia: A systematic review and meta-analysis. International Breastfeeding Journal. 2017; 12(44). DOI: $10.1186 / \mathrm{s} 13006-017-0133-x$.

18. Khanal V, Scott JA, Lee AH, Karkee R, Binns CW. Factors associated with early initiation of breastfeeding in Western Nepal. Int. J. Environ. Res. Public Health 2015, 12, 95629574; DOI: 10.3390/ijerph120809562.

19. Andreas N, Kampmann B, Mehring Le-Doare K. Human breast milk: A review on its composition and bioactivity. Early Human Development, 2015; 91(11):629-635. doi.org/10.1016/j.earlhumdev.2015.08.013

20. Lissauer T, Fanaroff AA, Miall L, Fanaroff $\mathrm{J}$. Neonatology at a Glance, 4th Edition, eBook. ISBN: 978-1-119-51320-9 February 2020. Wiley-Blackwell.

21. Smith ER, Locks LM, Manji KP, McDonald $\mathrm{CM}$, Kupka R, Kisenge $\mathrm{R}$, et al. Delayed breastfeeding initiation is associated with infant morbidity. J Pediatr. 2017; 191:5762.e2. DOI:10.1016/j.jpeds.2017.08.069

22. World Health Organization. Hospital care for mothers and newborn babies: quality assessment and improvement tool. 2014. $2^{\text {nd }}$ Edition. Available from: http://www.euro.who.int/_data/assets/p df_file/0004/244831/Hospital-care-formothers-and-newborn-babies-qualityassessment-and-improvementtool.pdf?ua $=1$

23. Majra JP1, Silan VK. Continuation of breastfeeding in a tertiary care institute of Haryana: Journal of Clinical and Diagnostic Research. 2016; 10(9):16-20. DOI: 10.7860/JCDR/2016/19072.8559
24. UNICEF and WHO. The Baby-Friendly Hospital Initiative. Information at: https://www.who.int/activities / promotingbaby-friendly-hospitals/ten-steps-tosuccessful-breastfeeding.

25. Sartorio BT, Coca KP, Marcacine KO, Abuchaim, ESV, Abrão ACFV. Breastfeeding assessment instruments and their use in clinical practice. Rev Gaúcha Enferm. 2017 Mar; 38(1):e64675. DOI:10.1590/19831447.2017 .01

26. UNICEF. Report of the State of the World's Children 2016. A fair chance for every child. ISBN: 978-92-806-4838-6. Information from:

http://weshare.unicef.org/Package/2AMZI FFS4KH

27. Sharma IK, Byrne A. Early initiation of breastfeeding: a systematic literature review of factors and barriers in South Asia. Int Breastfeed J. 2016; 11(17):1-12. DOI: 10.1186/s13006-016-0076-7

28. Berde AS, Yalcin SS. Determinants of early initiation of breastfeeding in Nigeria: a population-based study using the 2013 demographic and health survey data. BMC Pregnancy Childbirth. 2016; 1-9. DOI: $10.1186 / \mathrm{s} 12884-016-0818-\mathrm{y}$

29. Beyene MG, Geda NR, Habtewold TD, Assen ZM. Early initiation of breastfeeding among mothers of children under the age of 24 months in Southern Ethiopia. Int Breastfeed $\mathrm{J}$ [Internet]. 2017; 1-9. Available from: http://dx.doi.org/10.1186/s13006-0160096-3 